\title{
EDUCAÇÃO E DIREITOS HUMANOS: DESAFIOS PARA A ESCOLA CONTEMPORÂNEA
}

\author{
Angela Viana Machado Fernandes \\ Melina Casari Paludeto ${ }^{* *}$
}

\begin{abstract}
RESUMO: A educação voltada aos direitos humanos ainda não faz parte da prática nem do currículo da escola brasileira. Em momentos de crise de valores públicos e privados e da sociedade como um todo, torna-se imperativo que as temáticas da igualdade e da dignidade humana não estejam inscritas apenas de textos legais, mas que, igualmente, sejam internalizadas por todos que atuam tanto na educação formal como na não formal.
\end{abstract}

Palavras-chave: Direitos humanos. Educação. Formação de professores.

\section{EDUCATION AND HUMAN RIGHTS: CHALLENGES FOR CONTEMPORARY SCHOOL}

ABSTRACT: Education focused on Human Rights is not yet part of the practice or curriculum of the Brazilian schools. In times when public and private values, and the whole society are in crisis, the issue of equality and human dignity has not only to be part of texts, but also to be internalized by anyone who works either in formal or non-formal education.

Key words: Human rights. Education. Teachers training.

* Doutora em Educação e professora do Departamento de Ciências da Educação e do Programa de Pós-Graduação em Educação Escolar da Universidade Estadual Paulista (UNESP, campus de Araraquara). E-mail: angela@fclar.unesp.br

** Graduada em Sociologia pela UnEsp e membro do Grupo de Pesquisa "Educação, Juventude e Direitos Humanos”. E-mail: mel_paludeto@yahoo.com.br 


\section{A} discussão internacional sobre direitos humanos iniciou-se logo após o genocídio imposto pelo nazismo na Segunda Guerra, culminando com a Declaração Universal dos Direitos Humanos de 1948 e ratificada na Declaração Universal de Direitos Humanos de Viena, em 1993. Estas declarações introduzem uma concepção de direitos humanos universais e indivisíveis. Entretanto, a discussão sobre cidadania nos parece preceder a dos direitos.

O estudo clássico de T. H. Marshall (1967) discorre sobre a evolução dos direitos do cidadão diante das desigualdades inerentes à sociedade de classes. É a cidadania, apoiada na igualdade entre os cidadãos e na participação plena do indivíduo, em todas as instâncias, que permitirá que as desigualdades dos sistemas de classes possam ser confrontadas, ou seja, a desigualdade pode ser aceitável, desde que a igualdade da cidadania seja reconhecida. Através do desenvolvimento histórico dos direitos do cidadão na sociedade inglesa, o autor focaliza o conceito segundo uma tríplice dimensão: o direito civil, o político e o social.

Os direitos civis referem-se às liberdades individuais, liberdade de ir e vir, liberdade de imprensa, pensamento e fé, o direito à propriedade e à conclusão de contratos válidos e o direito à justiça. São os tribunais de justiça que garantirão os direitos civis, através da igualdade perante a lei.

Os direitos políticos garantem a participação dos indivíduos no exercício do poder político, ora como membros de um organismo investido de autoridade política (partidos, sindicatos, associações), ora como eleitores dos membros de tal organismo. As instituições encarregadas de garantir estes direitos são o Parlamento e as câmaras representativas locais.

Finalmente, os direitos sociais referem-se ao bem-estar econômico e segurança ao direito de participar, por completo, na herança social, levando uma vida de ser civilizado de acordo com os padrões que prevalecem na sociedade (consumo, lazer, segurança). O sistema educacional e os serviços sociais deverão garantir estes direitos. A educação é um pré-requisito necessário à liberdade civil, pois os direitos civis se destinam a ser utilizados por pessoas inteligentes e de bom senso, que aprenderam a ler e escrever.

$\mathrm{O}$ autor discute a incorporação dos direitos civis, no século XVIII, dos direitos políticos, no século XIX, e dos sociais, no século XX. 
A cidadania é considerada como um status concedido aos indivíduos que são membros integrais da sociedade. Os que o possuem são iguais com respeito aos direitos e deveres pertinentes a este status. Independente da desigualdade de classes, a igualdade de status é mais importante que a igualdade de renda. Nesta evolução, os direitos são entendidos sempre como concessôes e não como conquistas.

É a partir destas categorias que o sistema internacional de proteção aos direitos do homem enfatiza o que veio a ser denominado "era dos direitos". Bobbio (1992) afirma que o problema do fundamento do direito está no que se tem de fato e no que se gostaria de ter. Os direitos humanos são coisas desejáveis e merecem ser perseguidos. Pode-se afirmar que, de acordo com o contexto histórico, novos direitos devem ser assegurados, o que nos leva a certo relativismo.

Pinsky (2003), por sua vez, afirma que ser cidadão é ter direito à vida, à liberdade, à propriedade, à igualdade perante a lei, ou seja, ter direitos civis. É também ter direitos políticos (votar e ser votado) e direitos civis, o que garante a participação de todos na riqueza coletiva: trabalho, educação de qualidade, salário justo, saúde, uma velhice tranquila, a informação não manipulada, a proteção do planeta, informaçōes sobre a bioética e suas consequências, alimentação saudável e para todos, enfim, o respeito às suas escolhas.

Estes só podem ser assegurados se houver um Estado democrático que entenda que todos são cidadãos livres e iguais em dignidade e direito. A dignidade, nesse sentido, torna-se um valor fundamental, essencial aos seres humanos. Enquanto a Organização das Nações Unidas (ONU) construíam as bases para sua Carta de Direitos Humanos, no Brasil vivíamos a total violação dos direitos com a ditadura militar.

Miranda (2006, p. 33-36) afirma que foi durante a Ditadura que os direitos humanos começaram a ser reivindicados pelos movimentos da sociedade civil. Dentre estes, destacam-se: o Movimento Feminino pela Anistia e a luta da Arquidiocese de São Paulo contra a tortura, abrigando humanamente os perseguidos políticos em seu estabelecimento. A resistência a atos arbitrários estendeu-se pelo país: de 1974 a 1978, muitos deputados e senadores ligados ao partido MDB, oposição na época, conseguiram se eleger e denunciar institucionalmente a violação dos direitos humanos. 
Educação e direitos humanos: desafios para a escola contemporânea

Vários foram os fatos que marcaram os anos de 1970 e 1980. Em meados de 1985, o movimento pelas "Diretas Já" reuniu diferentes segmentos da sociedade para eleições diretas para presidente da República. Mesmo não obtendo sucesso, os diferentes grupos, movimentos sociais e comunidades de base conseguiram participar da elaboração da Constituição, por meio das emendas populares, plebiscito e audiências públicas. Logo após a Constituição de 1988, no Brasil, houve em 1989 a ratificação da Convenção de Haia, dos Direitos da Criança e dos Adolescentes e, em 1990, foi aprovado o Estatuto da Criança e do adolescente (ECA) e a Lei de Diretrizes e Bases da Educação (LDB n. 9.394/1996).

O ECA (Lei n. 8.069 de julho de 1990), em suas disposições preliminares, afirma que esta lei dispõe sobre a proteção integral à criança e ao adolescente. Considera-se criança até 12 anos incompletos e adolescente de 12 a 18 anos. É dever da família, comunidade, sociedade e do poder público assegurar os direitos à vida, saúde, alimentação, educação, esporte, lazer, profissionalização, cultura, dignidade, respeito, liberdade e convivência familiar. Estes direitos serão prioritários nas políticas públicas. Nenhuma criança ou adolescente deve sofrer negligências, discriminação, exploração etc.

A criança e o adolescente têm direito à liberdade, que compreende: direito de ir e vir; de opinião e expressão; de crença e culto religioso; de brincar, praticar esportes e divertir-se; de participar da vida comunitária sem discriminação. É dever de todos velar pela dignidade de ambos, pondo-os a salvo de qualquer tratamento desumano ou violento.

Ao mesmo tempo, o Estatuto prevê que toda criança e adolescente tem direito à educação, sendo de sua obrigação visar o pleno desenvolvimento da pessoa, preparo para o exercício da cidadania e qualificação para o trabalho, assegurando-lhes: igualdade de condições para o acesso e permanência na escola; direito de ser respeitado por seus educadores; direito de contestar critérios avaliativos; direito de organização e participação em entidades estudantis; acesso à escola pública e gratuita nas proximidades de sua residência; é também dever do Estado assegurar ensino fundamental obrigatório e gratuito (Artigo 208 da Constituição). Da mesma forma, os pais têm a obrigação de matricular seus filhos na rede regular de ensino e os dirigentes 
de estabelecimentos de ensino fundamental, o dever de comunicar ao Conselho Tutelar (criado a partir desta lei) quando houver maus tratos, faltas injustificadas e elevados níveis de repetência. Nesse sentido, deverão ser respeitados os valores culturais, artísticos e históricos próprios do contexto social das crianças.

É proibido qualquer trabalho à criança até 14 anos (alterado para 16), ao adolescente aprendiz até 14 anos é assegurada bolsa de aprendizagem. É vedado trabalho noturno, insalubre e em horários que não permitam a frequência à escola. Todos devem prevenir a violação dos direitos das crianças e adolescentes. As emissoras de rádio e tevê somente exibirão, no horário recomendado, programas com finalidades educativas. É proibida a venda de armas, bebidas alcoólicas, fogos de artifício, bilhetes lotéricos etc.

O ECA afirma que a lei deveria ser implementada por meio de um conjunto de ações governamentais e não governamentais, da União, estados, Distrito Federal e municípios, por meio dos conselhos municipais, estaduais e nacional dos direitos da criança e do adolescente.

O Estatuto trata, ainda, da prática de atos infracionais, dos direitos e garantias das crianças e adolescentes mediante estes atos e das medidas a serem tomadas neste contexto de infração; define também as competências do Conselho Tutelar; da justiça da infância e da juventude. De acordo com Miranda (2006), cabe ao Conselho Tutelar identificar crianças em situação de negligência, miséria, abandono, exploração, violência, em qualquer lugar, mesmo no ambiente doméstico, e encaminhá-las à rede de proteção dos direitos.

Após a elaboração e aprovação do ECA, pudemos observar diferentes movimentos tanto de apoio e ampliação da lei como contra o espírito do estatuto. A ideologia que perpassa os grupos que acreditam que esta lei é protecionista está fundamentada tanto na menoridade penal, que passaria de 18 para 16 anos, como nas diferentes concepções sobre o trabalho infantil.

Contudo, antes de aprofundarmos nossa análise sobre direitos humanos e como este aparece nos documentos oficiais, como os PCNEM e o PNEDH, descreveremos nosso entendimento sobre educação como sendo este conceito, em si mesmo, um direito humano. É na educação como prática de liberdade, na reflexão, que o indivíduo toma para si seus direitos como fatos e realidade. O grande diferencial, neste 
Educação e direitos humanos: desafios para a escola contemporânea

momento, encontra-se no processo educativo, ou seja, na transmissão de conhecimentos anteriormente adquiridos em vivência social, que cada região ou país carrega consigo como história. E é por isso que a educação, seja ela familiar, comunal ou institucional, se constitui como um direito, um direito humano. É, pois, através dela que reconhecemos o outro, os valores, os direitos, a moral, a injustiça, nos comunicamos, ou seja, os elementos que nos cercam enquanto indivíduos sociais. Aliás, o movimento da história se faz possível através da transmissão às novas gerações das aquisições prévias da cultura humana, isto é, através da educação.

Entendendo que a educação é um direito, as lutas pela educação pública, gratuita, obrigatória e laica ganham espaço no contexto nacional. Observa-se, a partir do final da década passada e início desta, a expansão do ensino fundamental e a abertura para novas vagas no ensino médio; o Estado começa a focar na educação básica, influenciado pelas exigências das instituições financeiras internacionais, como FMI e Banco Mundial.

O direito ao acesso à educação básica, pelos dados do IBGE de 2000, ainda não tinha sido universalizado, pois 3,95\% da população de 7 a 9 anos e 6,39\% de 10 a 14 anos estavam fora da escola; dos analfabetos funcionais e absolutos, 42.844 .220 de pessoas acima de 10 anos, ou seja, $31,4 \%$ da população desta faixa etária, ainda não liam nem escreviam.

Além do acesso, a permanência, que deveria ser mantida, não o foi. Os índices de evasão e repetência eram de 19,5\% em 2002. De 100 alunos que tinham acesso ao ensino fundamental, apenas 59 terminavam a oitava série e 40 chegavam ao final de ensino médio (MEC/ INEP, 2002).

Assegurar o direito à educação significa não só o acesso e permanência, mas a qualidade do ensino, estruturas escolares adequadas, condições básicas de trabalho aos profissionais da escola, enfim, tornar as leis um fato, ou seja, sair do texto e se direcionar para o contexto.

Sendo assim, o acesso e a permanência se configuram como sendo uma das discussões que permeiam os direitos humanos voltados à educação. Porém, existem aquelas que se concentram no âmbito moral e ético, defendendo que estes valores deveriam se apresentar 
como inerentes ao processo educativo, ou seja, não se trata do como ensinar ou do que ensinar, mas a partir de quais princípios está baseada a educação.

Assim, os Parâmetros Curriculares Nacionais (PCN) afirmam, logo em sua introdução, que a cidadania deve ser compreendida como produto de histórias sociais protagonizadas pelos grupos sociais, sendo, nesse processo, constituída por diferentes tipos de direitos e instituições. O debate sobre a questão da cidadania é hoje diretamente relacionado com a discussão sobre o significado e o conteúdo da democracia, sobre as perspectivas e possibilidades de construção de uma sociedade democrática. A democracia pode ser entendida, em um sentido restrito, como um regime político. Para Bobbio (1986, p. 18), ela deve ser entendida como

(...) um conjunto de regras (primárias ou fundamentais) que estabelecem quem está autorizado a tomar as decisões coletivas e com quais procedimentos. (...) A regra fundamental da democracia é a regra da maioria, na qual são consideradas as decisões coletivas.

Um dos primeiros princípios é o da igualdade. De acordo com Comparato (2004), a desigualdade é a marca registrada da sociedade brasileira, desde seus primórdios. Além da desigualdade econômica, o autor afirma que nossos costumes e nossa ordem social possibilitam as diferenças sociais e, no Brasil, não existe um respeito pela lei; ela é uma regra geral abstrata que põe todos em pé de igualdade, o que não coincide em nada com a realidade. Vivemos em um regime de organização patrimonialista que não se propõe a igualdade, mas a indiferença pelos pobres, pelos moradores de rua, pelas favelas, pelos negros, pelos "com" educação e "sem" educação.

Outro princípio é o da tolerância e respeito à diversidade cultural. A ideia de cidadania contempla direitos civis, sociais, políticos e econômicos, os quais são a base da democracia. Bobbio (2002) afirma que a tolerância implica o uso da persuasão perante os que pensam diferente de nós, e não a imposição. A tolerância implica o reconhecimento de conviver com ideias opostas sem tornar as opiniōes irredutíveis. Soares (2006) compreende que os direitos humanos estão ligados a valores culturais e, por isso, é importante o olhar multicultural em relação ao outro. 
O modo de produção capitalista tornou a educação um instrumento de reprodução das desigualdades inerentes ao sistema de classes. E a sociedade de consumo trouxe consigo a ideia de concorrência, na qual os consumidores tornaram-se mercadorias. Neste sentido, Saviani (2004, p. 157) justifica a falta de investimento no setor educacional decorrente da prioridade política brasileira, que teria maior interesse em investir em setores privados ou até mesmo em outros setores, do que na educação, devido a um caráter "da própria estrutura da sociedade capitalista que subordina invariavelmente as políticas sociais à política econômica", adquirindo esta um caráter financeiro que passará a assumir as políticas sociais, dando origem à "abordagem neoliberal das políticas públicas". Igualdade e direitos humanos em um mundo pela globalização neoliberal excludente não se coadunam, daí a necessidade do respeito a ideias como o multiculturalismo.

O Plano Nacional de Educação em Direitos Humanos (PNEDH), de 2006, afirma que a educação em direitos humanos é compreendida como um processo sistemático e multidimensional que orienta a formação do sujeito de direitos, articulando as seguintes dimensóes:

a) apreensão de conhecimentos historicamente construídos sobre direitos humanos e a sua relação com os contextos internacional, nacional e local;

b) afirmação de valores, atitudes e práticas sociais que expressem a cultura dos direitos humanos em todos os espaços da sociedade;

c) formação de uma consciência cidadã capaz de se fazer presente nos níveis cognitivo, social, ético e político;

d) desenvolvimento de processos metodológicos participativos e de construção coletiva, utilizando linguagens e materiais didáticos contextualizados;

e) fortalecimento de práticas individuais e sociais que gerem açôes e instrumentos em favor da promoção, da proteção e da defesa dos direitos humanos, bem como da reparação das violaçôes. Sendo a educação um meio privilegiado na promoção dos direitos humanos, cabe priorizar a formação de agentes públicos e sociais para atuar no campo formal e não formal, abrangendo 
os sistemas de educação, saúde, comunicação e informação, justiça e segurança, mídia, entre outros. (Brasil, 2006)

O documento assinala que, desse modo, a educação é compreendida como um direito em si mesmo e um meio indispensável para o acesso a outros direitos. A educação ganha, portanto, mais importância quando direcionada ao pleno desenvolvimento humano e às suas potencialidades, valorizando o respeito aos grupos socialmente excluídos. Essa concepção de educação busca efetivar a cidadania plena para a construção de conhecimentos, o desenvolvimento de valores, atitudes e comportamentos, além da defesa socioambiental e da justiça social.

Nos termos já firmados no Programa Mundial de Educação em Direitos Humanos (PMDH, 2005, p. 25),

(...) a educação contribui também para: a) criar uma cultura universal dos direitos humanos; b) exercitar o respeito, a tolerância, a promoção e a valorização das diversidades (étnico-racial, religiosa, cultural, geracional, territorial, físico-individual, de gênero, de orientação sexual, de nacionalidade, de opção política, dentre outras) e a solidariedade entre povos e naçôes; c) assegurar a todas as pessoas o acesso à participação efetiva em uma sociedade livre.

Os temas transversais - contidos nos PCN - enfatizam a importância do trabalho com valores que, por sua vez, requerem uma reflexão ética como eixo norteador, por envolver posicionamentos e concepções a respeito de suas causas e efeitos, de sua dimensão histórica e política.

A ética é um dos temas mais trabalhados do pensamento filosófico contemporâneo (Brasil, 1996). A reflexão ética traz à luz a discussão sobre a liberdade de escolha. A ética interroga sobre a legitimidade de práticas e valores consagrados pela tradição e pelo costume. Abrange tanto a crítica das relações entre os grupos, dos grupos nas instituiçóes e ante elas, quanto a dimensão das ações pessoais. Trata-se, portanto, de discutir o sentido ético da convivência humana nas suas relações com várias dimensões da vida social: o ambiente, a cultura, o trabalho, o consumo, a sexualidade, a saúde.

"A educação em direitos humanos, ao longo de todo o processo de redemocratização e de fortalecimento do regime democrático, tem 
Educação e direitos humanos: desafios para a escola contemporânea

buscado contribuir para dar sustentação às ações de promoção, proteção e defesa dos direitos humanos, e de reparação das violaçôes" (Brasil, 2006, p. 26). Entretanto, o modelo educacional decorrente dos valores sociais não tem sido bem visto pela sociedade e por técnicos que atuam no contexto educacional. A instituição escolar não tem conseguido se transformar, ainda que seja um espaço privilegiado para atuação e reflexão.

Não existem agentes institucionais que dêem conta de trabalhar temas como prevenção a drogas, violência, sexualidade, alteridade, ética, entre outros. Porém, o documento afirma que a "consciência sobre os direitos individuais, coletivos e difusos tem sido possível devido ao conjunto de açóes de educação desenvolvidas, nessa perspectiva, pelos atores sociais e pelos(as) agentes institucionais que incorporaram a promoção dos direitos humanos como princípio e diretriz" (idem, ibid.). A implementação do PNEDH visa, sobretudo,

(...) difundir a cultura de direitos humanos no país, o que prevê a disseminação de valores solidários, cooperativos e de justiça social, uma vez que o processo de democratização requer o fortalecimento da sociedade civil, a fim de que seja capaz de identificar anseios e demandas, transformando-as em conquistas que só serão efetivadas, de fato, na medida em que forem incorporadas pelo Estado brasileiro como políticas públicas universais. (Brasil, 2006, p. 26)

São objetivos gerais do PNEDH:

a) destacar o papel estratégico da educação em direitos humanos para o fortalecimento do Estado democrático de direito; b) enfatizar o papel dos direitos humanos na construção de uma sociedade justa, equitativa e democrática; c) encorajar o desenvolvimento de ações de educação em direitos humanos pelo poder público e pela sociedade civil, por meio de ações conjuntas; d) contribuir para a efetivação dos compromissos internacionais e nacionais com a educação em direitos humanos; e) estimular a cooperação nacional e internacional na implementação de ações de educação em direitos humanos; f) propor a transversalidade da educação em direitos humanos nas políticas públicas, estimulando o desenvolvimento institucional e interinstitucional das ações previstas no PNEDH nos mais diversos setores (educação, saúde, comunicação, cultura, segurança e justiça, esporte e lazer, entre outros); g) avançar nas açōes e propostas do Programa Nacional de Direitos Humanos, no que se refere às 
questōes da educação em direitos humanos; h) orientar políticas educacionais direcionadas para a constituição de uma cultura de direitos humanos; i) estabelecer objetivos, diretrizes e linhas de ações para a elaboração de programas e projetos na área da educação em direitos humanos; j) estimular a reflexão, o estudo e a pesquisa voltados para a educação em direitos humanos; k) incentivar a criação e o fortalecimento de instituições e organizações nacionais, estaduais e municipais na perspectiva da educação em direitos humanos; l) balizar a elaboração, implementação, monitoramento, avaliação e atualização dos planos de educação em direitos humanos dos estados e municípios; $\mathrm{m}$ ) incentivar formas de acesso às açôes de educação em direitos humanos a pessoas com deficiência. (Brasil/PNEDH, 2006, p. 26-27)

Por outro lado, os PCN elaborados em 1997 indicam, entre outros, como objetivos do ensino fundamental, que os alunos sejam capazes de:

- compreender a cidadania como participação social e política, assim como exercício de direitos e deveres políticos, civis e sociais, adotando, no dia a dia, atitudes de solidariedade, cooperação e repúdio às injustiças, respeitando o outro e exigindo para si o mesmo respeito;

- posicionar-se de maneira crítica, responsável e construtiva nas diferentes situações sociais, utilizando o diálogo como forma de mediar conflitos e de tomar decisões coletivas;

- conhecer características fundamentais do Brasil nas dimensões sociais, materiais e culturais, como meio para construir progressivamente a noção de identidade nacional e pessoal e o sentimento de pertinência ao país.

A temática da pluralidade cultural nos temas transversais, nas Diretrizes Curriculares do governo federal, diz respeito ao conhecimento e à valorização de características étnicas e culturais dos diferentes grupos sociais que convivem no território nacional, às desigualdades socioeconômicas e à crítica às relações sociais discriminatórias e excludentes, que permeiam a sociedade brasileira, oferecendo ao aluno a possibilidade de conhecer o Brasil como um país complexo, multifacetado e, algumas vezes, paradoxal. Este tema propõe uma concepção que busca explicitar a diversidade étnica e cultural que compõe a sociedade brasileira, compreender suas relações, marcadas 
Educação e direitos humanos: desafios para a escola contemporânea

por desigualdades socioeconômicas, e apontar transformações necessárias, oferecendo elementos para a compreensão de que valorizar as diferenças étnicas e culturais não significa aderir aos valores do outro, mas respeitá-los como expressão da diversidade, respeito que é, em si, devido a todo ser humano, por sua dignidade intrínseca, sem qualquer discriminação. A afirmação da diversidade é traço fundamental na construção de uma identidade nacional que se põe e se repõe permanentemente, tendo a Ética como elemento definidor das relações sociais e interpessoais.

Ao contrário, principalmente no que se refere à discriminação, segundo o documento, é impossível compreendê-la sem recorrer ao contexto socioeconômico em que acontece e à estrutura autoritária que marca a sociedade. As produções culturais não ocorrem "fora" de relações de poder: são, por sua vez, constituídas e marcadas por ele, envolvendo um permanente processo de reformulação e resistência. Ambas, desigualdade social e discriminação, articulam-se no que se convencionou denominar "exclusão social", ou seja, impossibilidade de acesso aos bens materiais e culturais produzidos pela sociedade e de participação na gestão coletiva do espaço público - pressuposto da democracia (Brasil, 1996).

Entretanto, assinala o documento, apesar da discriminação, da injustiça e do preconceito que contradizem os princípios da dignidade, do respeito mútuo e da justiça, paradoxalmente, o Brasil tem produzido também experiências de convívio e reelaboração das culturas de origem, constituindo algo intangível que se tem chamado de brasilidade, que permite a cada um reconhecer-se como brasileiro. Por isso, no cenário mundial, o Brasil representa uma esperança de superação de fronteiras e de construção da relação de confiança na humanidade. A singularidade que permite esta esperança é dada por sua constituição histórica peculiar no campo cultural.

O que se almeja, portanto, ao tratar de pluralidade cultural, não é a divisão ou o esquadrinhamento da sociedade em grupos culturais fechados, mas o enriquecimento propiciado a cada um e a todos pela pluralidade de formas de vida, pelo convívio e pelas opções pessoais, assim como o compromisso ético de contribuir com as transformações necessárias à construção de uma sociedade mais justa. Reconhecer e valorizar a diversidade cultural é atuar sobre um dos 
mecanismos de discriminação e exclusão, entraves à plenitude da cidadania para todos e, portanto, para a própria nação (Brasil, 1996).

Formação de professores para/em direitos humanos

Em relação à formação de professores para/em direitos humanos, podemos constatar que ainda é recente e, num certo sentido, tímida a introdução desta temática ao conteúdo formativo dos docentes em geral. Isso se deve ao fato de serem poucos os sistemas de ensino, os centros de formação de educadores e de organizaçōes que trabalham nesta perspectiva. Somado a isso, a desvalorização docente parece senso comum.

O documento do PNEHD propõe que o professor insira a educação em direitos humanos nas diretrizes curriculares; integre esta educação aos conteúdos, metodologias e formas de avaliação dos sistemas de ensino; estimule os professores e colegas à reflexão e discussão do mesmo; desenvolva uma pedagogia participativa; torne a educação em direitos humanos um elemento relevante aos alunos, em todos os níveis; fomente a discussão de temas como gênero e identidade, raça e etnia, orientação sexual e religião, entre outras; apoie a formação de grêmios e conselhos escolares. Enfim, são 27 pontos de orientação para que a equipe escolar trabalhe a temática com os alunos e a comunidade.

A inclusão de novos conteúdos a serem trabalhados por professores na educação formal prescinde da ideia que os mesmos tenham sobre o ECA ou mesmo sobre direitos. Infelizmente, no Brasil, ainda não superamos a ideia de que propostas, leis e ações programáticas devem ser discutidas com os docentes. São estes os atores dos quais podemos obter ou não adesão frente a um novo paradigma. A educação informal, ou seja, em grupos marginalizados por etnia, gênero, dependentes químicos, jovens oriundos da Fundação CASA, classe social, entre outros, parece obter maior resultado quando se discute valores, direitos e deveres.

Nesse aspecto, nos aponta Candau (2008, p. 83), um ponto de partida que se considera fundamental é não conceber os professores como "meros técnicos, instrutores, responsáveis unicamente pelo ensino de diferentes conteúdos e por funçôes de normalização e 
disciplinamento". Para que haja, de fato, a formação de professores em direitos humanos, é necessário que estes sejam percebidos como profissionais mobilizadores de processos pessoais e grupais de natureza cultural e social.

É difícil implementar uma política sem que haja um engajamento maior, não só de professores, mas da família da comunidade e, principalmente, do Estado. Como discutir impunidade com alunos que assistem a um "tudo acaba em pizza" por parte de quem está no poder? A relação escola-sociedade é dialética e exige profundas reflexões em tempos de medo, da publicidade do que é privado, da inércia de diretores, professores e pais que parecem desistir da moral, da ética. A educação multicultural vem introduzindo novos valores, como africanidades brasileiras e igualdade para todos, e tenta ressignificar o olhar para os marginalizados. Nesse sentido, o Plano Nacional de Direitos Humanos pode e deve contribuir não só para o debate, mas para a implementação de políticas inclusivas na rede de ensino regular.

A propagação dos PNEDH vem obrigando as universidades e outros centros de formação de professores a cada vez mais discutirem e tomarem posição em relação ao conteúdo abordado neles, principalmente no que concerne aos temas transversais e à relação entre transversalidade e interdisciplinaridade como causa primária da organização curricular. Assim, para uma prática em direitos humanos, não se faz necessário que se introduza uma disciplina específica, mas que se entenda o currículo ora como interdisciplinar, ora como transversal. Ou seja, a necessidade é que se compreenda a problemática dos direitos humanos como algo capaz de impregnar todo o processo educativo, questionar as diferentes práticas desenvolvidas na escola, desde a seleção dos conteúdos até os problemas de organização escolar. Sem dúvida que este não é papel único do docente em sala de aula, mas de uma sociedade que se diz democrática e que pode possibilitar uma educação libertadora. Entretanto, isso só ocorrerá quando assumirmos nossos preconceitos e nossas dificuldades em aceitar o outro tal qual se configura.

\section{Considerações finais}

Ao que nos parece, já caminhamos um pouco para uma prática que efetivamente contenha os princípios dos direitos humanos, basta 
referirmo-nos aos PNEDH, aos PCNEM, a projetos de organizações não governamentais (ONGs) que trabalham em locais onde o Estado não chega, como as periferias urbanas que acolhem os sem-trabalho, os sem escola, os sem casa, os sem direitos. Outros representam as incansáveis tentativas de implementação desta problemática nas licenciaturas por todo o país, principalmente em função daquilo que o Brasil tem representado no cenário mundial: uma esperança de superação de fronteiras e de construção da relação de confiança na humanidade. Dados reais bastante representativos, mas que ainda não contemplam a totalidade $\mathrm{da}$ realidade brasileira. A educação voltada para os direitos humanos ainda não faz parte da prática nem do currículo da escola como deveria. Em momentos de crise de valores públicos e privados e da sociedade como um todo, torna-se imperativo que a temática da igualdade e da dignidade humana não faça parte apenas de textos legais, mas que, igualmente, seja internalizada por todos que atuam tanto na educação formal como na não formal. E aqui podemos propor não só revisão curricular, mas a formação docente para que inclua em seu programa os direitos humanos, que são para todos e cuja proposta aconteça de fato e de direito.

Recebido em abril de 2010 e aprovado em agosto de 2010.

\section{Referências}

BOBBIO, N. O futuro da democracia: uma defesa das regras do jogo. Rio de Janeiro: Paz \& Terra, 1986.

BOBBIO, N. A era dos direitos. Rio de Janeiro: Campus, 1992.

BOBBIO, N. Elogio da serenidade e outros escritos morais. São Paulo: UNESP, 2002.

BRASIL. (Constituição 1988). Constituição da República Federativa do Brasil. Brasília, DF: Senado, 1988.

BRASIL. Comitê Nacional de Educação em Direitos Humanos. Plano Nacional de Educação em Direitos Humanos. Brasília, DF: Secretaria Especial dos Direitos Humanos; MEC, 2006.

BRASIL. Declaração e Programa de ação da Conferencia Mundial sobre os Direitos Humanos. Viena, 1993. 
Educação e direitos humanos: desafios para a escola contemporânea

BRASIL. Lei n. 8.069, de 13 de julho de 1990. Dispõe sobre o Estatuto da Criança e do Adolescente e dá outras providências. Diário Oficial da União, Brasília, DF, 16 jul 1990.

BRASIL. Lei n. 9.394, de 20 de dezembro de 1996. Estabelece as diretrizes e bases da educação. Diário Oficial da União, Brasília, DF, 23 dez. 1996.

BRASIL. Ministério da Educação. Secretaria de Educação Fundamental. Parâmetros curriculares nacionais: apresentação dos temas transversais. Brasília, DF: MEC/SEF, 1997.

BRASIL. Ministério da Educação. Secretaria de Educação Fundamental. Parâmetros curriculares Nacionais: introdução aos parâmetros curriculares nacionais. Brasília, DF: MEC/SEF, 1997.

BRASIL. Ministério de Educação. Instituto Nacional de Estudos e Pesquisas Educacionais (INEP), 2002.

BRASIL. Plano Mundial de Educação para Todos. Brasília, DF: Secretaria de Direitos Humanos, 2005.

BRASIL. Programa Nacional de Educação em Direitos Humanos, decreto n. $7037,2006$.

CANDAU, V.M.F. Educação em direitos humanos e formação de professores/as. In: Scavino, S.; Candau, V.M.F. (Org.). Educação em direitos humanos: temas, questôes e propostas. Petrópolis: DP et alii, 2008.

COMPARATO, F.K. O princípio da igualdade e da escola. In: CARVALHO, J.S. Educação, cidadania e direitos humanos. Petrópolis: Vozes, 2004. p. 66-84.

FELDMAN, M.G. (Org.). Formação de professores e escola na contemporaneidade. São Paulo: SENAC, 2009.

MARSHALL, T.H. Cidadania, classe social e status. Rio de Janeiro: Zahar, 1967.

MIRANDA, N. Por que Direitos Humanos. Belo Horizonte: Autêntica 2006. 
PINSKY, J. Introdução. In: Pinsky J.; Pinsky, C.B. Historia da cidadania. São Paulo: Contexto, 2003. p. 9-13.

SACAVINO, S. Educação para a paz e a não-violência: formação em serviço de professores/as. In: SCAVINO, S.; CANDAU, V.M.F. (Org.). Educação em direitos humanos: temas, questôes e propostas. Petrópolis: DP et alii, 2008. p. 119- 130.

SAVIANI, D. Da nova LDB ao Novo Plano Nacional de Educação: por uma outra política educacional. 5. ed. Campinas: Autores Associados, 2004 .

SOARES, L.E. Legalidade libertária. Rio de Janeiro: Lumem Júris, 2006. 